\title{
Sinus Rhythm
}

National Cancer Institute

\section{Source}

National Cancer Institute. Sinus Rhythm. NCI Thesaurus. Code C100076.

An electrocardiographic finding of an atrial rhythm which originates from the sinoatrial node that is considered normal for the population. (CDISC) 